\title{
A possible nonvisual function of the lateral geniculate nuclei in the white rat
}

\author{
ROBERT THOMPSON \\ Louisiana State University, Baton Rouge, Louisiana 70803
}

\begin{abstract}
After learning either a maze habit or an active avoidance response, rats underwent either enucleation of the eyes or bilateral destruction of the lateral geniculate nuclei or occipital cortex. Savings scores disclosed that the rats with lateral geniculate or occipital lesions were significantly inferior to the enucleated group in retention of the maze. While occipital lesions impaired retention of the avoidance habit, lateral geniculate lesions did not. Neither geniculate nor occipital lesions impaired retention of an incline plane discrimination learned in the absence of vision.
\end{abstract}

It has been reported that lesions of the occipital cortex impair performance of certain previously learned responses, such as a maze habit and an active avoidance response, that are neither dependent upon nor guided by visual cues (Lashley, 1943; Lubar, Schostal, \& Perachio, 1967; Thompson, 1974). The specific nonvisual function of the occipital cortex, however, remains unknown. According to the results of the current study, the lateral geniculate nuclei may also have a nonvisual function.

\section{METHOD}

Adult male albino rats of the Wistar strain were trained on either an incline plane discrimination problem (approach an upward sloping arm and avoid a downward sloping arm in a single unit $\mathrm{T}$-maze), a 3-cul maze habit, or an active avoidance response (jump out of a box within $10 \mathrm{sec}$ in order to avoid footshock). In the former situation, the rats were deprived of their eyes and subsequently trained on the discrimination habit. The subjects trained on the maze and avoidance habits had their eyes intact. The specific training procedures used to study the incline plane problem, the maze habit, and the avoidance response were the same as those reported by Thompson and Thorne (1973), Thompson (1974), and Thompson (1976), respectively.

Following learning, the majority of subjects sustained either bilateral electrolytic lesions to the lateral geniculate nuclei or bilateral aspirative ablations of the occipital cortex. The remaining animals served either as normal controls or were blinded by enucleation. After a recovery (or rest) period of 2 weeks, all animals were required to relearn the problem that was mastered preoperatively. Error savings scores constituted the measure of retention.

Following the retention test, histological verification of the locus and extent of the lesions was carried out. Details of the histological (and surgical) procedures have been reported elsewhere (Thompson, 1971).

\section{RESULTS}

The mean number of errors committed during original learning of the incline plane, maze, and avoidance habits was $18.9,16.5$, and 3.8 , respectively.

This research was supported in part by a grant from the Graduate Council on Research, Louisiana State University.
Table 1

Mean Percentage Error Savings Scores for all Groups

\begin{tabular}{|c|c|c|c|c|c|c|}
\hline \multirow[b]{2}{*}{ Group } & \multicolumn{2}{|c|}{ Incline Plane } & \multicolumn{2}{|c|}{ Maze } & \multicolumn{2}{|c|}{ Avoidance } \\
\hline & $\mathbf{N}$ & Mean & $\mathbf{N}$ & Mean & $\mathbf{N}$ & Mean \\
\hline Control & 4 & 93.7 & 4 & 97.5 & 4 & 100 \\
\hline Blind & & & 4 & $73.5^{*}$ & 4 & 87.5 \\
\hline Lateral geniculate & 4 & 76.8 & 5 & $-13.2^{*}$ & 4 & 62.5 \\
\hline Occipital cortex & 4 & 85.5 & 5 & $-67.5^{*}$ & 5 & $-25.0 *$ \\
\hline
\end{tabular}

*Differed from the controls at least at the .05 level (Mann-Whitney test)

Table 1 summarizes the error savings scores for all groups. With respect to the incline plane problem, none of the differences in savings scores earned by the three groups approached statistical significance. In contrast, all three experimental groups involved on the maze task earned savings scores which were significantly inferior to those of the controls. It is important to note that the groups sustaining either geniculate or occipital damage, while earning significantly poorer savings scores than the enucleated group, did not differ significantly from each other. Concerning the avoidance habit, the occipital group earned savings scores which were significantly inferior to those earned by each of the remaining three groups. No other differences approached statistical significance.

Figure 1 shows representative lesions to the lateral geniculate nuclei. All animals sustaining occipital lesions suffered virtually complete damage to Areas 17,18 , and 18a of Krieg (1946).

Ancillary behavioral observations revealed that the rats with lateral geniculate lesions tended to be hyperactive, hypersensitive to footshock, and aggressive toward their cage mates and toward the experimenter. The occipitalectomized rats, on the other hand, appeared indistinguishable from the controls.

\section{DISCUSSION}

The results of the present study confirm earlier findings (Lashley, 1943; Lubar et al., 1967; Thompson, 1974) in showing 


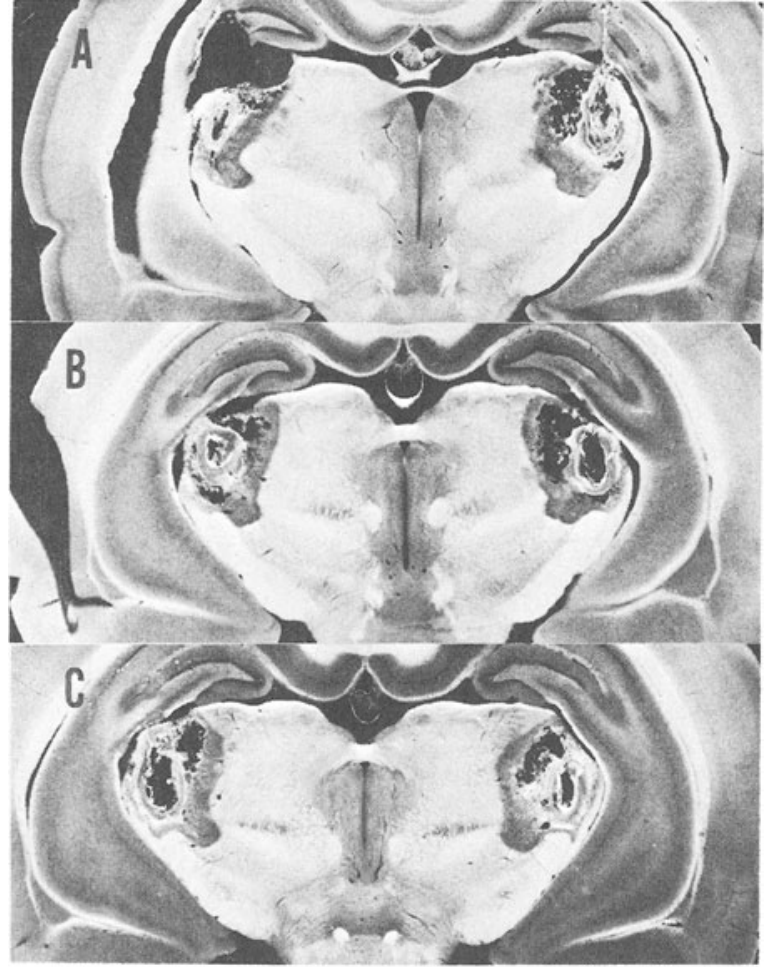

Figure 1. Photographs of unstained sections showing lesions to the lateral geniculate nuclei in one rat (saves $=-100 \%$ ) trained on the maze (A), another (savings $=50 \%$ ) trained on the avoidance habit $(B)$, and a third (savings $=75 \%$ ) trained on the incline plane problem (C).

that lesions of the occipital cortex impair retention of both a maze habit and an active avoidance response. The fact that the occipital groups trained on these two problems earned poorer retention scores than the respective enucleated groups emphasizes the nonvisual character of the deficits. The findings concerning the lateral geniculate nuclei suggest a nonvisual function for this thalamic structure as well, but only within the context of the maze situation.

Lashley (1943) proposed that the nonvisual function of the occipital cortex is based upon a nonspecific facilitatory effect that this structure exerts upon other neocortical regions. This view, however, suffers from the observation that occipital ablation does not interfere with the performance of other learned responses, such as an incline plane discrimination (cur- rent study) or latch box problems (Lashley, 1935; Spiliotis \& Thompson, 1973). According to the results of the present study, the nonvisual function of the occipital cortex in maze performance may be dependent upon the interconnectivity existing between the occipital cortex and the lateral geniculate nuclei, possibly involving a reticulo-dorsal lateral geniculooccipital (Scheibel \& Scheibel, 1958) pathway. and/or an occipito-ventral lateral geniculo-posterior thalamic (Horel, 1968) pathway. A study involving smaller lesions than those shown in Figure 1 would be needed to determine the precise geniculate (or possibly extrageniculate) focus for maze deficits.

Finally, the overall pattern of results emerging from occipital and geniculate damage (the former abolishes both a maze habit and an active avoidance response, whereas the latter abolishes a maze habit only) suggests that the nonvisual function of the occipital cortex associated with maze learning may be quite different from that associated with avoidance learning.

\section{REFERENCES}

Hores, J. A. A visual function for the ventral nucleus of the lateral geniculate body. Anatomical Record, 1968, 160, 367.

KRIEG, W. J. S. Connections of the cerebral cortex: I. The albino rat: A. Topography of the cortical areas. Journal of Comparative Neurology, 1946, 84, 221-275.

LASHLEY, K. S. Studies of cerebral function in learning: XI. The behavior of the rat in latch box situations. Comparative Psychological Monographs, 1935, 11, 1-42.

LASHLEY, K. S. Studies of cerebral function in learning: XII. Loss of the maze habit after occipital lesions in blind rats. Journal of Comparative Neurology, 1943, 79, 431-462.

Lubar, J. F., Schostal, C. J., \& Perachio, A. A. Nonvisual functions of visual cortex in the cat. Physiology and Behavior, 1967, 2, 179-184.

Scheibel, M. E., \& Scheibel, A. B. Structural substrates for integrative patterns in the brain stem reticular core. In H. H. Jasper (Ed.), Reticular formation of the brain. Boston: Little, Brown, 1958.

Spiliotis, P. H., \& Thompson, R. The "manipulative response memory system" in the white rat. Physiological Psychology, 1973, 1, 101-114.

Tномpson, $R$. Introducing subcortical lesions by electrolytic methods. In R. D. Myers (Ed.), Methods in psychobiology. New York: Academic Press, 1971.

Tномpson, R. Localization of the "maze memory system" in the white rat. Physiological Psychology, 1974, 2, 1-17.

Tномpson, R. Entorhino-subicular lesions: Amnestic effects on an assortment of learned responses in the white rat. Bulletin of the Psychonomic Society, 1976, 8, 433-434.

Thompson, R., \& THORNE, B. M. Brainstem reticular formation lesions: Amnestic effects on learned habits in the rat. Physiological Psychology, 1973, 1, 61-70.

(Received for publication August 26, 1976.) 